\title{
Successful treatment with anti- programmed-death-1 antibody in a relapsed natural killer/T-cell lymphoma patient with multi-line resistance: a case report
}

\author{
Jianping Lai, Peng Xu, Xiaoliu Jiang, Shan Zhou and Anwen Liu*
}

\begin{abstract}
Background: Extranodal natural killer/T-cell lymphoma (NKTCL), nasal type, is an aggressive malignancy with poor prognosis. Currently, there is no recommended standard therapy for relapsed NKTCL.

Case presentation: A 37-year-old woman with lymphadenopathy was diagnosed with NKTCL by biopsy of an enlarged lymph node on the right side of her neck. Enhanced computed tomography revealed no metastasis. For this patient, we performed continuous chemotherapy followed by radiotherapy; however, nodule biopsy showed metastases in her lower limbs 3 months after radiotherapy, which confirmed disease progression. Unfortunately, the patient' $s$ temperature was persistently high and her skin ulcers could not be controlled well using multi-line treatment. Therefore, we attempted treatment with the anti-programmed-death-1 (PD-1) antibody, pembrolizumab. Surprisingly, the patient achieved clinical complete remission (CR) after four cycles of pembrolizumab treatment, despite having persistent detectable Epstein-Barr virus (EBV) DNA. Other molecular monitoring techniques were unavailable for this patient owing to the retrospective nature of the study. The only adverse event was soreness of the upper limb joints and muscles.
\end{abstract}

Conclusion: This relapsed NKTCL case treated with pembrolizumab showed that multimodal therapy including pembrolizumab would be partially or totally effective for relapsed NKTCL.

Keywords: Salvage treatment, Anti-PD-1 Antibody, Relapsed NKTCL

\section{Background}

Extranodal natural killer/T-cell lymphoma (NKTCL) is recognized as a distinct lymphoma based on the World Health Organization (WHO) classification [1]. It is found to be more prevalent in East Asia, as well as in Central and South America; simultaneously it is a rare but Epstein-Barr virus (EBV)-related lymphoma with poor outcomes [2]. Besides the nasal cavity, skin is the second most frequent extranodal site for NKTCL [3]. No randomized controlled trial has been conducted because of its rarity, and most therapeutic regimens are

\footnotetext{
* Correspondence: awliu666@163.com

Department of oncology, The Second Affiliated Hospital of Nanchang University, Nanchang 330006, China
}

(c) The Author(s). 2017 Open Access This article is distributed under the terms of the Creative Commons Attribution 4.0 International License (http://creativecommons.org/licenses/by/4.0/), which permits unrestricted use, distribution, and reproduction in any medium, provided you give appropriate credit to the original author(s) and the source, provide a link to the Creative Commons license, and indicate if changes were made. The Creative Commons Public Domain Dedication waiver (http://creativecommons.org/publicdomain/zero/1.0/) applies to the data made available in this article, unless otherwise stated.

consensus-guided. Radiotherapy, chemotherapy, and combined chemoradiotherapy are usually effective for localized NKTCLs; however, recurrence is common. Although clinical complete remission (CR) after primary treatment has been achieved in the majority of patients [4-7], a proportion of them relapse subsequently. To date, there have been few studies on treatment of relapsed NKTCL and few results are available. The optimal management for relapsed NKTCL, especially distant recurrence, has yet to be defined.

Recently, because of the demonstration of tumormediated immunosuppression mechanisms, cancer immunotherapy has achieved significant breakthroughs. When immune checkpoint pathways were blocked by 
drugs, impressive clinical responses were observed in diverse types of human cancers [8]. Recent studies of programmed-death-1 (PD-1) blockade in lymphomas have made astounding advances, contributing to the further development of novel immunotherapies for these tumors [9]. However, the effectiveness of anti-PD-1 antibodies in patients with relapsed NKTCL is unknown. In the present case report, we describe a patient with distant relapsed NKTCL who received salvage treatment with an anti-PD-1 antibody.

\section{Case presentation}

A 37-year-old female had noticed a mass on her right neck for about 2 weeks before her initial visit to our hospital. A magnetic resonance imaging (MRI) scan of the nasopharynx and neck showed mucosal thickening in the right nasopharynx, together with multiple deep cervical lymph node enlargements. She was diagnosed with extranodal NKTCL by excisions biopsy (nasopharyngeal mass biopsy and cervical mass biopsy) and was transferred to our hospital in October 2014. Immunohistochemical staining demonstrated that the tumor cells expressed surface CD2, cytoplasmic CD3 , TIA-1, and granzyme B, but not CD10, CD15, CD20, CD21, and PAX-5. Bone marrow examination showed no presence of neoplastic cells. She was confirmed as having Ann Arbor stage IIE extranodal NKTCL based on the radiological findings and laboratory tests. She underwent four cycles of interchangeable chemotherapy comprising VIPD (etoposide, ifosfamide, cisplatin, and dexamethasone) and AspaMet (pegaspargase and methotrexate), followed by involved-field radiotherapy, and achieved complete remission. In August 2015, cutaneous nodules appeared on her lower limbs, which were proved to be relapsed NKTCL by biopsy, without involvement of the marrow. Immunophenotype showed that the nodules were $\mathrm{CD}^{+}, \mathrm{CD}^{-} 0^{-}$, $\mathrm{CD}^{+} 0^{+}, \mathrm{CD} 6^{+}, \mathrm{CD}^{-}$, TIA- $1^{+}$, Granzyme B ${ }^{+}, \mathrm{Ki}-67^{+}$: $95 \%$, $\mathrm{TCR}^{-}$, and EBERs ${ }^{+}$. The patient developed a fever, with her temperature reaching as high as $40{ }^{\circ} \mathrm{C}$ after two cycles of the AspaMet regimen. Positron emission tomographycomputed tomography (PET-CT) scans revealed multiple patchy shadows on her skin and in the subcutaneous tissue of her upper limbs and lower limbs, which accumulated radioactivity. The lymph nodes of her right armpit and bilateral groin also showed radioactive accumulation. She was switched to P-GemOx (gemcitabine, oxaliplatin, and pegaspargase) and was admitted to hospital for infected lower limb ulcers after one cycle. She was switched again to a combined Chidamide and EPOCH $80 \%$ (ifosfamide, cyclophosphamide, vincristine, pirarubicin, and dexamethasone) regimen. After the first cycle, her temperature decreased to normal levels. However, the patient developed a recurrent fever and the ulcerous areas expanded when the drugs were withdrawn (Fig. 1a).
Therefore, she was treated with a combined gemcitabine, pegaspargase, dexamethasone, and doxorubicin regimen, after which the ulcerous areas narrowed and her temperature dropped slightly, accompanied by grade 4 myelosuppression. Her temperature and ulcers could not be controlled well when the fourth cycle chemotherapy was carried out. She then received another combined regimen comprising camptothecin, paclitaxel, mitoxantrone, and methylprednisolone, combined with apatinib; however, she developed infliction and chest tightness during the third day of treatment. The infliction and chest tightness remained when apatinib was given alone. An enhanced computed tomography scan showed no involvement of her organs, except the skin of lower limbs; PETCT was unavailable. She was then treated with pembrolizumab (at a dose of $2 \mathrm{mg} / \mathrm{kg}$ every 21 days) from August 17, 2016. The skin ulcers got better after the end of the first cycle (Fig. 1b). Her performance status improved and the lower limbs ulcers had almost healed after four cycles (Fig. 1c). At this time, EBV DNA remained persistently detectable. After another seven cycles of treatment, EBV DNA became undetectable (Fig. 2). Radiological findings and PET-CT images after pembrolizumab therapy were not performed because of the patient's refusal. The patient developed soreness of the upper limb joints and muscles, as well as a mild increase in uric acid during therapy. These symptoms were controlled well by diet control, and did not reappear after further pembrolizumab therapy. No other treatment-related adverse events were observed.

\section{Discussion and conclusions}

The recommended standard protocol for localized NKTCL has evolved greatly over the last decade. Radiotherapy combined with chemotherapy is recommended for those cases with stage I-II nasal disease [10, 11]. However, an optimal treatment modality for relapsed NKTCL remains unclear at present. The choice of salvage treatment is associated with the type of primary regimen and response duration. Currently, the preferred treatment for relapsed NKTCLs is L-asparaginasecontaining regimens, such as dexamethasone, methotrexate, ifosfamide, L-asparaginase, and etoposide (SMILE) or L-asparaginase, methotrexate, and dexamethasone (Aspa Met Dex). Kwong et al. [12] defined the efficacy of the SMILE regimen in patients with relapsed NKTCL. The Aspa Met Dex regimen was evaluated in a multicenter phase 2 clinical trial [13], where CR rate was $61.1 \%$ in 19 relapsed/refractory NKTCL patients. Efficacy of L-asparaginase-based regimen is still suboptimal for relapsed/refractory NKTCL. Gemcitabine has an impressive effect on L-asparaginase refractory NKTCL. Wang et al. [14] reported promising results for the P-GemOx regimen for newly diagnosed advanced stage or relapsed extranodal NKTCL, in which the 

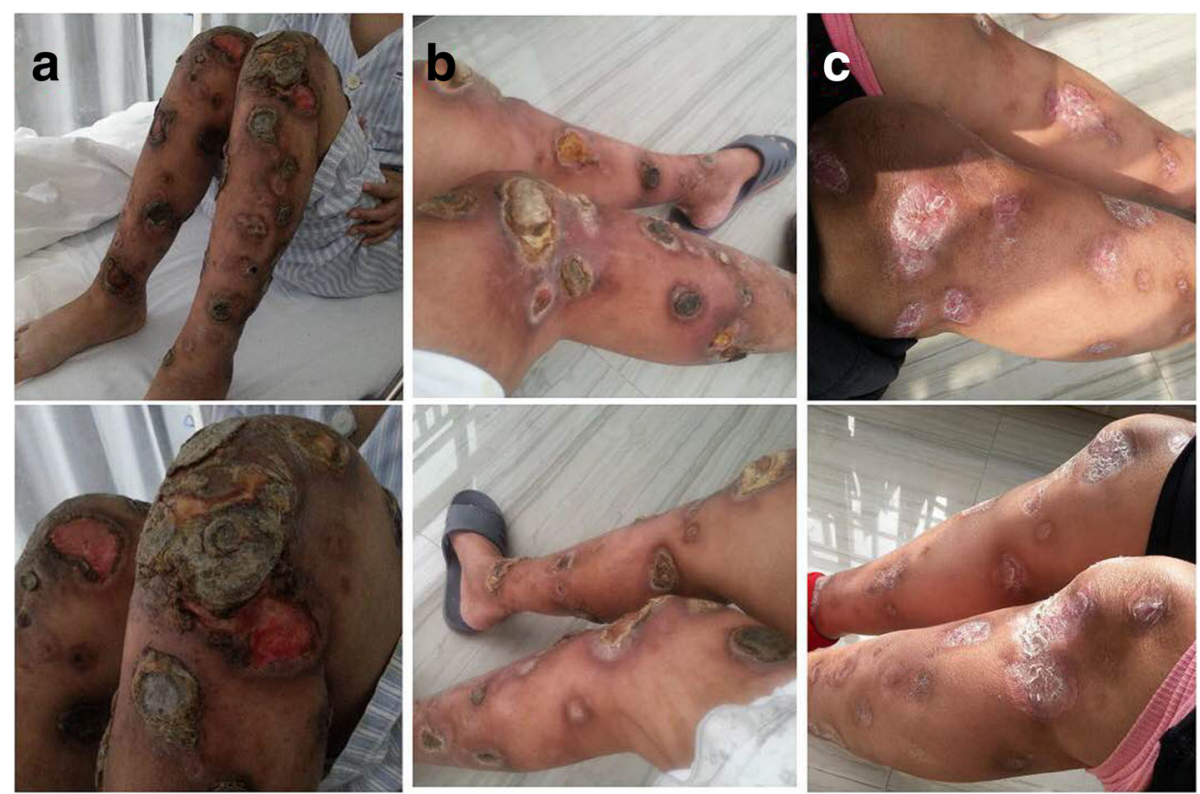

Fig. 1 Double lower limbs ulcers after relapse. a Before pembrolizumab. b Response to pembrolizumab after one cycle of treatment. c Ongoing response to pembrolizumab after four cycles of treatment

overall response rate (ORR) was $80 \%(28 / 35)$ and the CR rate was $51.4 \%(18 / 35)$. With respect to the adverse events, grade $3 / 4$ myelosuppression was observed in $40.0 \%$ of patients, with no treatment-related deaths. Results from a multicenter phase II study of chidamide in patients with relapsed/refractory peripheral T-cell lymphoma led to approval of chidamide by the Chinese Food and Drug Administration [15]. However, the efficacy of chidamide-based combination regimens for relapsed NKTCL is uncertain. Zhou et al. [16] found that
DDGP (cisplatin, dexamethasone, gemcitabine, and pegaspargase) is an active regimen for the treatment of relapsed/refractory NKTCLs, with an ORR of $88.2 \%$ $(15 / 17)$. Although promising efficacy was achieved in advanced NKTCL patients treated with a combined regimen comprising pegaspargase, l-asparaginase, and gemcitabine, a part of them still experienced failure and progression.

In the past 10 years, survival of patients has been improved greatly by antibodies targeting immune checkpoints

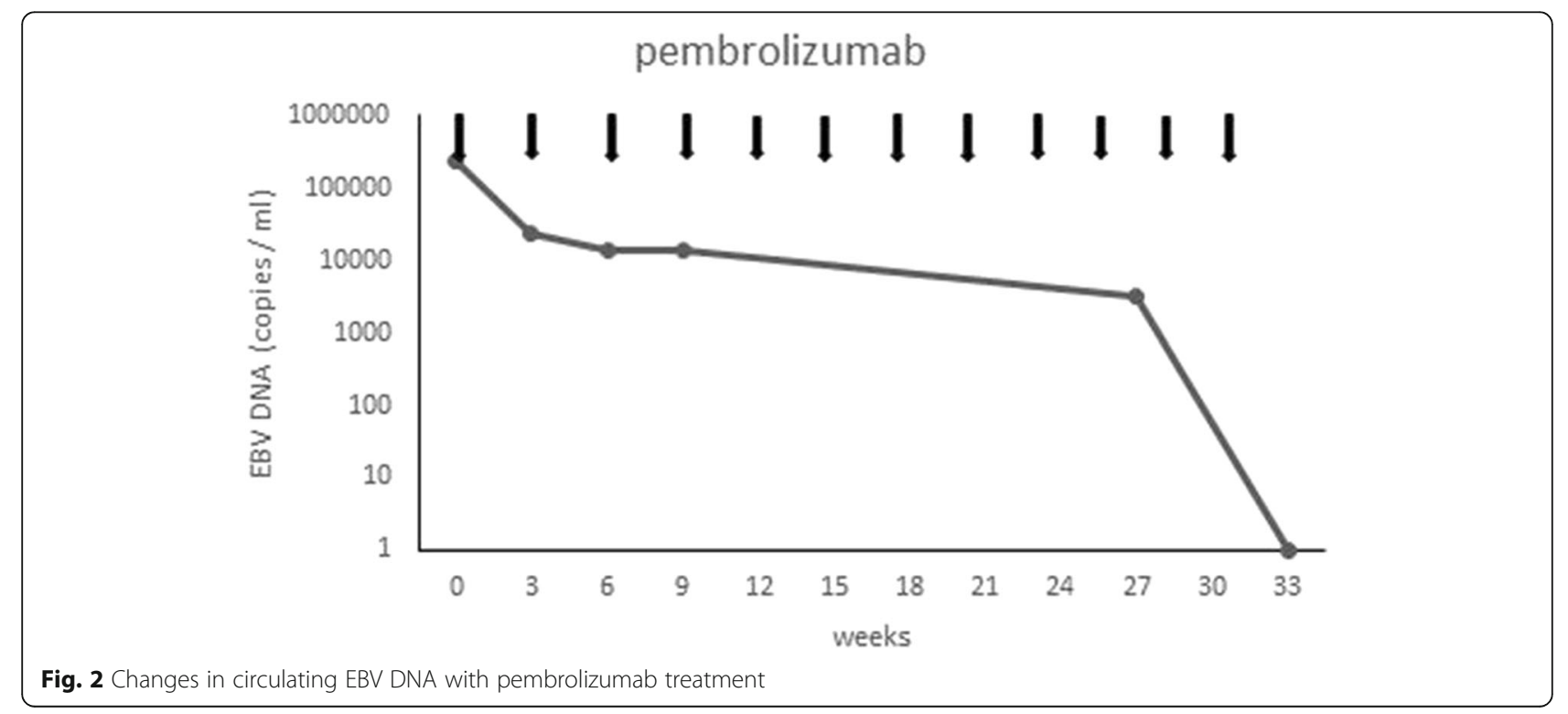


in a number of human cancers, such as melanoma, renal cancer, colon cancer, and lung cancer. NKTCL might also be targetable for therapeutic antibodies owing to $67 \%$ of NKTCL samples expressing PD-L1 [17]. Lastly, Kwong et al. [18] reported high efficacy of pembrolizumab in relapsed/refractory NKTCL that failed on L-asparaginase. There was a obvious response to skin lesions and EBV DNA level after the first cycle in a case that had biopsyproven cutaneous relapse. Similar results were observed in our case, which only involved the skin of the lower limbs skins. EBV DNA became undetectable only after the eleventh cycle. Our patient with only cutaneous relapse has experienced longer progression-free survival (PFS) and fewer side effects compared with those patients who had visceral organ involvement. Our case was meaningful because it proved that an anti-PD-1 antibody could be effective for selected patients with resistance to multi-line treatment.

In conclusion, we encountered a relapsed NTKCL patient with resistance to multi-line treatment, who responded well to the anti-PD-1 antibody pembrolizumab. This preliminary result suggested that pembrolizumab would be partially or totally effective for relapsed NKTCL.

\begin{abstract}
Abbreviations
Aspa Met Dex: L-asparaginase, methotrexate, and dexamethasone; AspaMet: Pegaspargase and methotrexate; CR: Complete remission; DDGP: Cisplatin, dexamethasone, gemcitabine, and pegaspargase; EBV: Epstein-Barr virus; EPOCH: Ifosfamide, cyclophosphamide, vincristine, pirarubicin, and dexamethasone; NKTCL: Natural killer/T-cell lymphoma; ORR: Overall response rate; PD-1: Programmed-death-1; PET-CT: Positron emissiontomography-computed tomography; PFS: Progression-free survival; P-GemOx: Pegaspargase, gemcitabine, and oxaliplatin; SMILE: Dexamethasone, methotrexate, ifosfamide, L-asparaginase, and etoposide; VIPD: Etoposide, ifosfamide, cisplatin, and dexamethasone
\end{abstract}

\section{Acknowledgements}

Not applicable.

\section{Funding}

No funding was obtained for this report.

\section{Availability of data and materials}

The datasets used and/or the analyzed current case report are available from the corresponding author upon reasonable request.

\section{Authors' contributions}

JPL participated in the case collection, drafting, and revising the manuscript. PX participated in drafting and revising the manuscript. XL and SZ participated in the case collection. AWL participated in the analysis and interpretation of the data, as well as in drafting and revising all versions of the manuscript. All authors read and approved the final manuscript.

\section{Ethics approval and consent to participate}

Reports describing the case of a single patient are exempt from review by the ethics committee of the Second Affiliated Hospital of Nanchang University. Authors obtained written informed consent and publication consent from the patient.

\section{Consent for publication}

Written informed consent was obtained from the patient for publication of this case report and accompanying images. A copy of the written consent is available for review by the editor of this journal.

\section{Competing interests}

The authors declare that they have no competing interests.

\section{Publisher's Note}

Springer Nature remains neutral with regard to jurisdictional claims in published maps and institutional affiliations.

Received: 8 March 2017 Accepted: 24 July 2017

Published online: 28 July 2017

\section{References}

1. Vose J, Armitage J, Weisenburger D. International peripheral T-cell and natural killer/T-cell lymphoma study: pathology findings and clinical outcomes. Journal of clinical oncology : official journal of the American Society of Clinical Oncology. 2008:26(25):4124-30.

2. Gualco G, Domeny-Duarte P, Chioato L, Barber G, Natkunam Y, Bacchi CE. Clinicopathologic and molecular features of 122 Brazilian cases of nodal and extranodal NKTT-cell lymphoma, nasal type, with EBV subtyping analysis. Am J Surg Pathol. 2011;35(8):1195-203.

3. Chia HY, Tey HL, Tan KB, Chong WS. Nasal-type extranodal natural killer/Tcell lymphoma presenting with extensive leg ulcers. Clin Exp Dermatol. 2009;34(8):e693-5.

4. Li YX, Yao B, Jin J, Wang WH, Liu YP, Song YW, Wang SL, Liu XF, Zhou LQ, $\mathrm{He} \mathrm{XH}$, et al. Radiotherapy as primary treatment for stage IE and IIE nasal natural killer/T-cell lymphoma. Journal of clinical oncology : official journal of the American Society of Clinical Oncology. 2006;24(1):181-9.

5. Bi XW, Jiang WQ, Zhang WW, Huang JJ, Xia Y, Wang Y, Sun P, Li ZM. Treatment outcome of patients with advanced stage natural killer/T-cell lymphoma: elucidating the effects of asparaginase and postchemotherapeutic radiotherapy. Ann Hematol. 2015;94(7):1175-84.

6. Wang L, Xia ZJ, Huang HQ, Lu Y, Zhang YJ. Cyclophosphamide, doxorubicin, vincristine, and prednisone (CHOP) in the treatment of stage IE/IIE extranodal natural killer/T cell lymphoma, nasal type: 13-year follow-up in 135 patients. Int J Hematol. 2012;96(5):617-23.

7. Kim M, Kim TM, Kim KH, Keam B, Lee SH, Kim DW, Lee JS, Jeon YK, Kim CW, Heo DS. Ifosfamide, methotrexate, etoposide, and prednisolone (IMEP) plus L-asparaginase as a first-line therapy improves outcomes in stage III/IV NKTT cell-lymphoma, nasal type (NTCL). Ann Hematol. 2015;94(3):437-44.

8. Topalian SL, Drake CG, Pardoll DM. Immune checkpoint blockade: a common denominator approach to cancer therapy. Cancer Cell. 2015;27(4):450-61.

9. Ansell SM, Lesokhin AM, Borrello I, Halwani A, Scott EC, Gutierrez M, Schuster SJ, Millenson MM, Cattry D, Freeman GJ, et al. PD-1 blockade with nivolumab in relapsed or refractory Hodgkin's lymphoma. N Engl J Med. 2015:372(4):311-9.

10. Kim WS, Song SY, Ahn YC, Ko YH, Baek CH, Kim DY, Yoon SS, Lee HG, Kang WK, Lee HJ, et al. CHOP followed by involved field radiation: is it optimal for localized nasal natural killer/T-cell lymphoma? Annals of oncology : official journal of the European Society for Medical Oncology. 2001;12(3):349-52.

11. Yamaguchi $M$, Tobinai K, Oguchi M, Ishizuka N, Kobayashi $Y$, Isobe $Y$, Ishizawa K, Maseki N, Itoh K, Usui N, et al. Concurrent chemoradiotherapy for localized nasal natural killer/T-cell lymphoma: an updated analysis of the Japan clinical oncology group study JCOG0211. Journal of clinical oncology : official journal of the American Society of Clinical Oncology. 2012;30(32):4044-6.

12. Kwong YL, Kim WS, Lim ST, Kim SJ, Tang T, Tse E, Leung AY, Chim CS. SMILE for natural killer/T-cell lymphoma: analysis of safety and efficacy from the Asia Lymphoma Study Group. Blood. 2012;120(15):2973-80.

13. Jaccard A, Gachard N, Marin B, Rogez S, Audrain M, Suarez F, Tilly H, Morschhauser F, Thieblemont C, Ysebaert L, et al. Efficacy of L-asparaginase with methotrexate and dexamethasone (AspaMetDex regimen) in patients with refractory or relapsing extranodal NK/T-cell lymphoma, a phase 2 study. Blood. 2011;117(6):1834-9.

14. Wang JH, Wang L, Liu CC, Xia ZJ, Huang HQ, Lin TY, Jiang WQ, Lu Y. Efficacy of combined gemcitabine, oxaliplatin and pegaspargase (P-gemox regimen) in patients with newly diagnosed advanced-stage or relapsed/refractory extranodal NK/T-cell lymphoma. Oncotarget. 2016;7(20):29092-101.

15. Shi Y, Dong M, Hong X, Zhang W, Feng J, Zhu J, Yu L, Ke X, Huang H, Shen $Z$, et al. Results from a multicenter, open-label, pivotal phase II study of chidamide in relapsed or refractory peripheral T-cell lymphoma. Annals of oncology : official journal of the European Society for Medical Oncology. 2015;26(8):1766-71. 
16. Zhou Z, Li X, Chen C, Li X, Zhang L, Li L, Wang X, Ma W, Fu X, Wu J, et al. Effectiveness of gemcitabine, pegaspargase, cisplatin, and dexamethasone (DDGP) combination chemotherapy in the treatment of relapsed/refractory extranodal NK/T cell lymphoma: a retrospective study of 17 patients. Ann Hematol. 2014;93(11):1889-94.

17. Kumai T, Kobayashi H, Harabuchi Y. Novel targets for natural killer/T-cell lymphoma immunotherapy. Immunotherapy. 2016;8(1):45-55.

18. Kwong YL, Chan TS, Tan D, Kim SJ, Poon LM, Mow B, Khong PL, Loong F, Au-Yeung R, lqbal J, et al. PD1 blockade with pembrolizumab is highly effective in relapsed or refractory NKT-cell lymphoma failing $\mathrm{L}$-asparaginase. Blood. 2017;129(17):2437-42.

Submit your next manuscript to BioMed Central and we will help you at every step:

- We accept pre-submission inquiries

- Our selector tool helps you to find the most relevant journal

- We provide round the clock customer support

- Convenient online submission

- Thorough peer review

- Inclusion in PubMed and all major indexing services

- Maximum visibility for your research

Submit your manuscript at www.biomedcentral.com/submit
Biomed Central 